\title{
Effect of EDTA and Phosphoric Acid Pretreatment on the Bonding Effectiveness of Self-Etch Adhesives to Ground Enamel
}

\author{
Ihab M. Ibrahima \\ Dina W. Elkassas ${ }^{b}$ \\ Mai M. Yousryc
}

\section{ABSTRACT}

Objectives: This in vitro study determined the effect of enamel pretreatment with phosphoric acid and ethylenediaminetetraacetic acid (EDTA) on the bond strength of strong, intermediary strong, and mild self-etching adhesive systems.

Methods: Ninety sound human premolars were used. Resin composite cylinders were bonded to flat ground enamel surfaces using three self-etching adhesive systems: strong Adper Prompt L-Pop ( $\mathrm{pH}=0.9-1.0)$, intermediary strong AdheSE $(\mathrm{pH}=1.6-1.7)$, and mild Frog $(\mathrm{pH}=2)$. Adhesive systems were applied either according to manufacturer instructions (control) or after pretreatment with either phosphoric acid or EDTA ( $n=10)$. After 24 hours, shear bond strength was tested using a universal testing machine at a cross-head speed of $0.5 \mathrm{~mm} /$ minute. Ultra-morphological characterization of the surface topography and resin/enamel interfaces as well as representative fractured enamel specimens were examined using scanning electron microscopy (SEM).

Results: Neither surface pretreatment statistically increased the mean shear bond strength values of either the strong or the intermediary strong self-etching adhesive systems. However, phosphoric acid pretreatment significantly increased the mean shear bond strength values of the mild self-etching adhesive system. SEM examination of enamel surface topography showed that phosphoric acid pretreatment deepened the same etching pattern of the strong and intermediary strong adhesive systems but converted the irregular etching pattern of the mild self-etching adhesive system to a regular etching pattern. SEM examination of the resin/enamel interface revealed that deepening of the etching pattern was consistent with increase in the length of resin tags. EDTA pretreatment had a negligible effect on ultra-morphological features.

Conclusions: Use of phosphoric acid pretreatment can be beneficial with mild self-etching adhesive systems for bonding to enamel. (Eur J Dent 2010;4:418-428)

Key words: Self-etch adhesives; Ground enamel; Bonding; SEM; Phosphoric acid pretreatment; EDTA pretreatment.

Assistant lecturer, Operative Dentistry Department Faculty of Oral and Dental Medicine, Cairo University, Cairo, Egypt.

b Lecturer, Operative Dentistry Department, Faculty of Oral and Dental Medicine, Misr International University, Cairo, Egypt.

- Associate Professor, Operative Dentistry Department, Faculty of Oral and Dental Medicine, Cairo University, Cairo, Egypt.

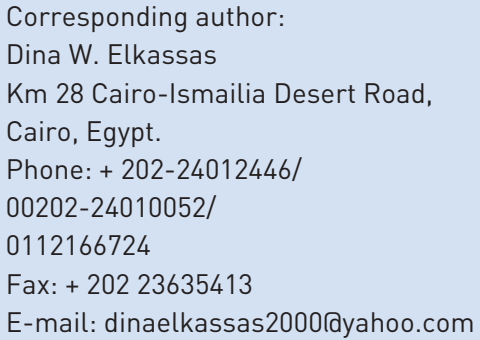




\section{INTRODUCTION}

The basic mechanism of bonding to enamel and dentin is essentially an exchange process involving replacement of minerals from the hard dental tissues with resin monomers, which, upon setting, become micro-mechanically interlocked in the created porosities. ${ }^{1}$

Contemporary adhesives can be classified on the basis of underlying adhesion strategy into 'etch-and-rinse', 'self-etch', and 'resin-modified glass-ionomer adhesives'. ${ }^{2}$ The success of the etch-and-rinse adhesives for bonding resin-based restorative materials to enamel and dentin is well supported by numerous studies and many years of clinical experience. ${ }^{3}$ The concept of self-etching adhesives is based on the use of polymerizable acidic monomers that simultaneously condition and prime both dentin and enamel. ${ }^{4}$ These adhesives are subdivided into three categories based upon their $\mathrm{pH}$ value: strong systems have a $\mathrm{pH}$ of 1 or below, intermediary strong systems have a $\mathrm{pH}$ of approximately 1.5 , and mild systems have a $\mathrm{pH}$ of 2 or more. ${ }^{5}$

The bond strength of self-etching adhesive systems to enamel is controversially discussed in the literature; some studies have reported comparable data to that observed with etch-and-rinse systems, ${ }^{6-8}$ while other studies considered them less reliable when bonding to enamel. ${ }^{9-12}$ There is still some concern that manufacturers are sacrificing enamel bond strength in their struggle for simplified and strengthened bonding to the more complex substrate, dentin, despite the fact that enamel is the 'front-gate' determinant of a restoration's longevity and durability.

Many conditioning agents have been used for surface pretreatment of enamel and dentin, including phosphoric, maleic, nitric, citric, and ethylenediaminetetraacetic (EDTA) acids. These acids are used to remove the smear layer and to demineralize the underlying enamel and dentin. ${ }^{13}$ One might consider pre-etching the enamel with phosphoric acid prior to application of a self-etching adhesive system. The effect of such additional etching on enamel bond strength is also controversially discussed in the literature. Its use might be beneficial with some self-etching adhesives, but this depends largely on the properties of the adhesive itself. ${ }^{14}$

It has been previously reported that etching of enamel surfaces with EDTA is not recommended because of its negligible non-uniform effect. ${ }^{15,16}$ However, the effect of EDTA pretreatment on bond strength of enamel in conjunction with self-etching adhesives has not, to our knowledge, yet been addressed in literature. The interaction of such a mild conditioning agent as a pretreatment agent with different $\mathrm{pH}$ categories of self-etching adhesive systems is a matter of speculation.

Thus, this study was designed to determine the effect of two surface pretreatment agents on the enamel bond strength of self-etching adhesive systems with different $\mathrm{pH}$ values. The null hypotheses were tested first: pretreatment of the ground enamel surfaces with phosphoric acid or EDTA had no effect on the shear bond strength of selfetch adhesives to enamel. Second, there was no difference in bond strengths between self-etching adhesive systems with different $\mathrm{pH}$ values when bonding to ground enamel.

\section{MATERIALS AND METHODS}

Preparation of specimens

A total of 90 sound extracted maxillary human premolars were used for shear bond strength testing. The teeth, excluding the buccal surface, were embedded in self-curing acrylic resin (Rapid Repair, DeguDent GmbH, Hanau, Germanyl by using a specially fabricated cuboidal Teflon mould $(3 \times 2 \times 1.3 \mathrm{~cm})$. The buccal enamel surface of the embedded premolars was ground on a watercooled mechanical grinder (TF250, JeanWirtz, Düsseldorf, Germanyl by using 180-grit abrasive paper to obtain flat enamel surfaces with a clinically relevant smear layer.

\section{Bonding procedures}

The acrylic resin blocks were placed in the mould. To standardize the bonding area, a piece of vinyl tape with a 3-mm diameter punctured hole was placed over the mid-coronal ground enamel surface. The teeth were assigned into three groups according to bonding procedure. In the first subgroup (control), no pretreatment agent was applied. In the second subgroup, etching was performed using 37\% phosphoric acid (PA) for 15 seconds (Total Etch; Ivoclar Vivadent AG, Schaan, Liechtenstein). In the third subgroup, surfaces were pretreated with $18.85 \%$ EDTA for 60 seconds (EDTA Odahcam; Dentsply, Latin America, Rio de 
Janeiro, Brazil). Adper Prompt L-Pop (APLP) (3M ESPE AG Dental Products, Seefeld, Germany), AdheSE (SE) (Ivoclar Vivadent AG, Schaan, Liechtenstein), or Frog (FG) (SDI Limited, Bayswater, Victoria, Australia) self-etch adhesive systems ( $n=10$ ) were then applied to the demarcated bonding area following manufacturers' instructions (Table 1). All adhesives were cured using a Bluephase C5 (Ivoclar Vivadent AG, Schaan, Liechtenstein) light emitting diode curing unit for 10 seconds at a light intensity of $500 \mathrm{~mW} / \mathrm{cm}^{2}$. The light intensity was periodically checked with the light meter integrated in the handpiece holder of the curing unit. The roof of the mould was then secured in place. The 2-mm-thick roof composed of two equal halves with a circular 3-mm diameter hole was used for the packing of the Tetric EvoCeram (shade $A_{3}$ ) (Ivoclar Vivadent AG, Schaan, Liechtenstein) resin composite. The composite was then light cured for 20 seconds using the same light curing unit according to manufacturer instructions.

\section{Shear bond strength testing}

After 24-hour storage in distilled water, the samples were subjected to compression testing using a mono-bevelled, chisel-shaped metallic rod in a computerized universal testing machine (Model LRX-plus; Lloyd Instruments Ltd., Fareham, UK). The specimens were stressed in shear at a cross-head speed of $0.5 \mathrm{~mm} / \mathrm{min}$. The shear force at failure was recorded and converted to shear stress in MPa units using computer software (Nexygen-4.1; Lloyd instruments Ltd., Fareham, UKJ.

\section{Fractographic analysis}

The fracture sites of the debonded surfaces were examined using a binocular stereomicroscope (SMZ-10, Nikon, Melville, NY, USA) at 15X magnification. Representative samples were chosen for examination under scanning electron microscopy (SEM) (XL 30, Philips, Eindhoven, Netherlands). Samples were mounted on SEM stubs and sputter-coated (Ladd Sputter Coater, Ladd Research Industries, Williston, Vermont, USA) with a thin layer of gold under vacuum. Examination was done at $30 \mathrm{kV}$ of accelerating voltage at different magnifications and characteristic photomicrographs were obtained at $1000 \mathrm{X}$ magnification.

\section{Statistical analysis}

Statistical analysis was performed with SPSS 14.0 (SPSS Inc., Chicago, Illinois, USA) for Windows. The significance level was set at $P \leq .05$. Two-way analysis of variance (ANOVA) was used in testing significance for the effect of both variables studied ladhesive system versus surface pretreatment agent) on the mean shear bond strength. Post-hoc Tukey's test was used for pair-wise comparison between the means when the ANOVA test was significant. Mode of failure was presented as percentages.

\section{SEM examination phy \\ Examination of the enamel surface topogra-}

Representative samples ( $\mathrm{n}=2$ ) were prepared and treated with the corresponding surface pretreatment agents and adhesive systems for each subgroup as described earlier. However, the steps of bonding component application and light curing were skipped in the case of the two-step selfetching adhesive systems used while the light curing step was skipped in the case of the single-step self-etching adhesive system. All specimens were then treated with a 60-second acetone rinse under ultrasonic movement (Ultrasonic Steri-Cleaner UC-150, Sturdy Industrial Co., Taipei, Taiwan) for the removal of any crystals and other residues from primers and left to air dry.

Examination of the resin/enamel interface

Additional representative samples $(n=2)$ were prepared using the same surface pretreatment agents, adhesive systems, and restorative resin composite used for shear bond strength testing. After 24-hour storage in distilled water, the bonded specimens were cut perpendicular to the resin/ enamel interface using a slow-speed diamond disc (K6974, Komet, Lemgo, Germany) under water lubrication. The cross-sectioned specimens were finished and polished under running water with OptiDisc (Kerr Corporation, Orange, California, USA) resin composite finishing and polishing discs from coarse/medium to fine to extra-fine grits. Specimens were ultrasonically cleaned for 5 minutes in distilled water. Polished interfaces were demineralized with $50 \%$ PA for 15 seconds, rinsed thoroughly with distilled water, and air dried. 
All specimens were gold sputtered under vacuum and examined using SEM at $30 \mathrm{kV}$ accelerating voltage. Images of the enamel surfaces topography were viewed at 2000X magnification, while those for resin-enamel interface analysis were examined at $3500 \mathrm{X}$ magnification.

\section{RESULTS}

Results of shear bond strength test

Table 2 shows the results of statistical analysis using two-way ANOVA test to describe the effect of both studied variables (adhesive system and surface pretreatment agent). Both adhesive systems and surface pretreatment agents had statistically significant effects on mean shear bond strength $(P<.001$ and $P=0.041$, respectively). The interaction between adhesive systems and surface pretreatment agents had a statistically significant effect on mean shear bond strength $(P=0.049)$.

The results of Tukey's test for the comparison between different interactions of adhesive systems with surface pretreatments are shown in Table 3. Comparing the 3 adhesive systems when applied according to manufacturer instructions, the intermediary strong self-etch adhesive system (SE) showed statistically highest shear bond strength values followed by the strong self-etching adhesive system (APLP) while the mild selfetch adhesive system (FG) showed the statistically lowest shear bond strength values. With regard to the effect of the different surface pretreatments, it was revealed that different surface pretreatments did not statistically affect the mean shear bond strength values of the intermediary strong selfetching adhesive system (SE). PA pretreatment did not affect its bond strength values of the APLP system; on the other hand, EDTA significantly reduced its bond strength values. However, PA pretreatment significantly increased the mean shear bond strength values of the mild self-etching adhesive system, which was not affected by EDTA pretreatment.

Results of failure mode analysis

Each fractured surface was allocated to one of five types: Type 1, adhesive failure between the bonding resin and enamel; Type 2: partial adhesive failure between the bonding resin and enamel and partial cohesive failure of the bonding resin; Type 3: partial adhesive failure between the bond- ing resin and enamel and partial cohesive failure of the enamel; Type 4: 100\% cohesive failure of the bonding resin; or Type 5: 100\% cohesive failure of the enamel.

Figure 1 shows a bar chart of the percentage distribution of failure modes, while Figure 2 represents SEM photomicrographs for the different types of failure modes. Type 4 was not encountered in any group. Fractographic analysis of the fractured sites revealed that adhesive failure (Type 1) was the predominating failure type. Without additional surface pretreatment, only the intermediary strong self-etching adhesive system showed cohesive failure of the enamel (Type 5).

The highest percentages of failure (Type 1) were found in the strong and mild self-etching adhesive system groups with $100 \%$ in no pretreatment and EDTA pretreatment and $90 \%$ in the PA pretreatment subgroups. In the intermediary strong self-etching adhesive system, Type 1 failure was seen $60 \%$ of the time with no pretreatment and PA pretreatment and 50\% with EDTA pretreatment. Type 2 failure (20\% and $30 \%$ ) was seen only in the intermediary strong self-etching adhesive system with PA and EDTA pretreatment subgroups, respectively. Type 3 failure was seen only in the same two subgroups (10\% in both). Type 5 failure was seen in the intermediary strong self-etching adhesive system group with different surface pretreatments and in the strong selfetching adhesive system and the mild self-etching adhesive system groups with PA pretreatment.

Results of SEM examination of enamel surface topography and interface

According to Cehreli and Altay, ${ }^{15}$ there are 5 types of etching patterns. Each of these types was used in the interpretation of the enamel surface topography photomicrographs: Type I, preferential dissolution of the prism cores resulting in a honeycomb-like appearance; Type II, preferential dissolution of the prism peripheries creating a cobblestone-like appearance; Type III, a mixture of type I and type II patterns; Type IV, pitted enamel surfaces as well as structures that look like unfinished puzzles, maps, or networks; and Type V, flat, smooth surfaces.

SEM photomicrographs of the surface topography and resin/enamel interface of the strong self-etching adhesive system are shown in Figure 
3. With no surface pretreatment, topographical ultra-morphological characterization (Figure 3a) showed predominant homogeneous deep preferential dissolution of the enamel prism peripheries with areas of prism core dissolution la Type III etching pattern). Meanwhile, interfacial ultramorphological characterization (Figure 3b) depicted resin infiltration in the form of a very thin hybrid-like layer with sparse, broad, and shallow

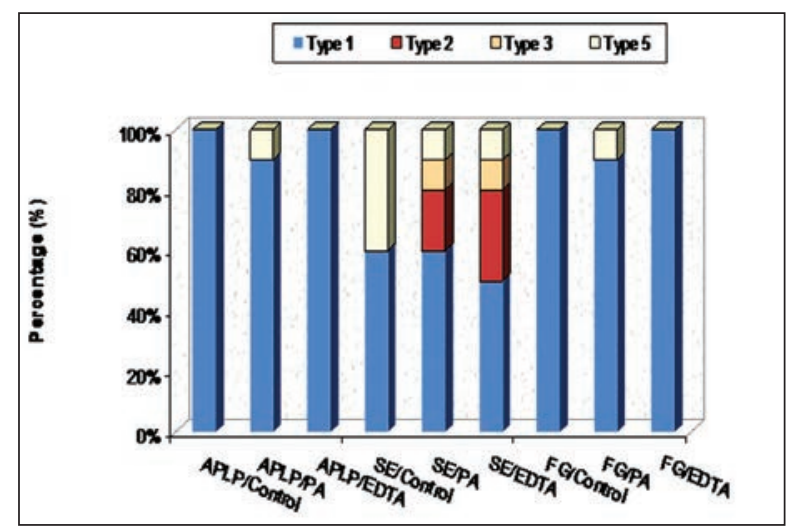

Figure 1. Percentage distribution of failure modes of all tested groups. tag-like structures. A thin continuous adhesive layer was evident between the tags and the overlaying resin composite. With PA pretreatment, enamel surface topography (Figure $3 \mathrm{c}$ ) showed progressively homogeneous and deeper Type III etching patterns. The interface (Figure 3d) revealed resin infiltration in the form of a broader hybrid-like layer with numerous tag-like structures penetrating deeper into the etched enamel. A thicker, continuous, and uniform adhesive layer was evident. With EDTA pretreatment, topography (Figure 3 e) revealed a milder, homogeneous Type I etching pattern. The enamel prisms were hollowed out to deep pits or craters placed side by side separated by thick interprismatic enamel persisting in the form of rings. The interface (Figure 3 f) closely resembled that of no surface pretreatment (Figure 3b).

SEM photomicrographs of the surface topography and resin/enamel interface of the intermediary strong self-etching adhesive system are shown in

Table 1. Materials composition, pH, manufacturer, composition and instructions for use

\begin{tabular}{|c|c|c|c|c|}
\hline Adhesive system & Manufacturer & Composition & Instructions for use & $\mathrm{pH}$ \\
\hline $\begin{array}{l}\text { AdheSE } \\
\text { (Two-step) }\end{array}$ & $\begin{array}{c}\text { Ivoclar Vivadent } \\
\text { AG, Schaan, } \\
\text { Liechtenstein }\end{array}$ & $\begin{array}{c}\text { Primer: phosphonic acid acrylate, bis-acrylamide, } \\
\text { water, initiators (camphorquinone and Lucirin), } \\
\text { and stabilizers. } \\
\text { Bonding component: HEMA, dimethacrylates, } \\
\text { highly dispersed silicon dioxide, initiators and } \\
\text { stabilizers. }\end{array}$ & $\begin{array}{l}\text { 1. Apply primer, agitate } \\
\text { for } 15 \text { s and leave for } 15 \mathrm{~s} \\
\text { allowing a total reaction } \\
\text { time of } 30 \text { s. Disperse excess } \\
\text { primer with a strong stream } \\
\text { of compressed air. } \\
\text { 2. Apply AdheSE Bond and } \\
\text { disperse with a very weak } \\
\text { stream of compressed air. } \\
\text { Light cure for } 10 \mathrm{~s}\end{array}$ & $1.6-1.7$ \\
\hline $\begin{array}{l}\text { Frog } \\
\text { (Two-step) }\end{array}$ & $\begin{array}{c}\text { SDI Limited, } \\
\text { Bayswater, } \\
\text { Victoria, Australia }\end{array}$ & $\begin{array}{c}\text { Primer: phosphoric acid ester monomer, HEMA, } \\
\text { dimethacrylate monomer, water, camphorquinone } \\
\text { and stabilizer. } \\
\text { Bonding component: phosphoric acid ester } \\
\text { monomer, HEMA, dimethacrylate monomer, } \\
\text { silicon dioxide filler, camphorquinone and } \\
\text { stabilizer. }\end{array}$ & $\begin{array}{l}\text { 1. Apply primer, leave in } \\
\text { place for } 20 \text { s then blow } \\
\text { gently with compressed air. } \\
\text { 2. Apply bond to the primed } \\
\text { surface and uniform } \\
\text { with a gentle stream of } \\
\text { compressed air Light cure } \\
\text { for } 10 \text { s }\end{array}$ & 2 \\
\hline
\end{tabular}

Table 2. Descriptive statistics using two-way ANOVA for the adhesive systems and surface pretreatment agents.

\begin{tabular}{l|cccc}
\hline Source of variation & Sum of squares & DF & Mean square & $f$-value \\
\hline Adhesive system & 590.357 & 2 & 295.179 & 21.842 \\
$\begin{array}{l}\text { Surface pretreatment agent } \\
\begin{array}{l}\text { Adhesive system versus surface } \\
\text { pretreatment agent }\end{array}\end{array}$ & 89.622 & 2 & 44.811 & 3.316 \\
\hline
\end{tabular}

DF: Degrees of freedom, *: Significant at $P \leq .05$ 
Figure 4. With no surface pretreatment, the topography (Figure 4a) had an irregular Type III etching pattern. The interface (Figure 4b) depicted resin infiltration in the form of a very thin hybrid-like layer with thick and shallow penetrating tag-like structures. The thin adhesive layer was evident. With PA pretreatment, the topography (Figure 4c) had a deeper mixed etching pattern (Type III) with areas that were less intensely etched. The interface (Figure $4 \mathrm{~d}$ ) revealed resin infiltration in the form of a broader hybrid-like layer with numerous deeply penetrating tag-like structures. A thick, uniform, and continuous adhesive layer was evi-
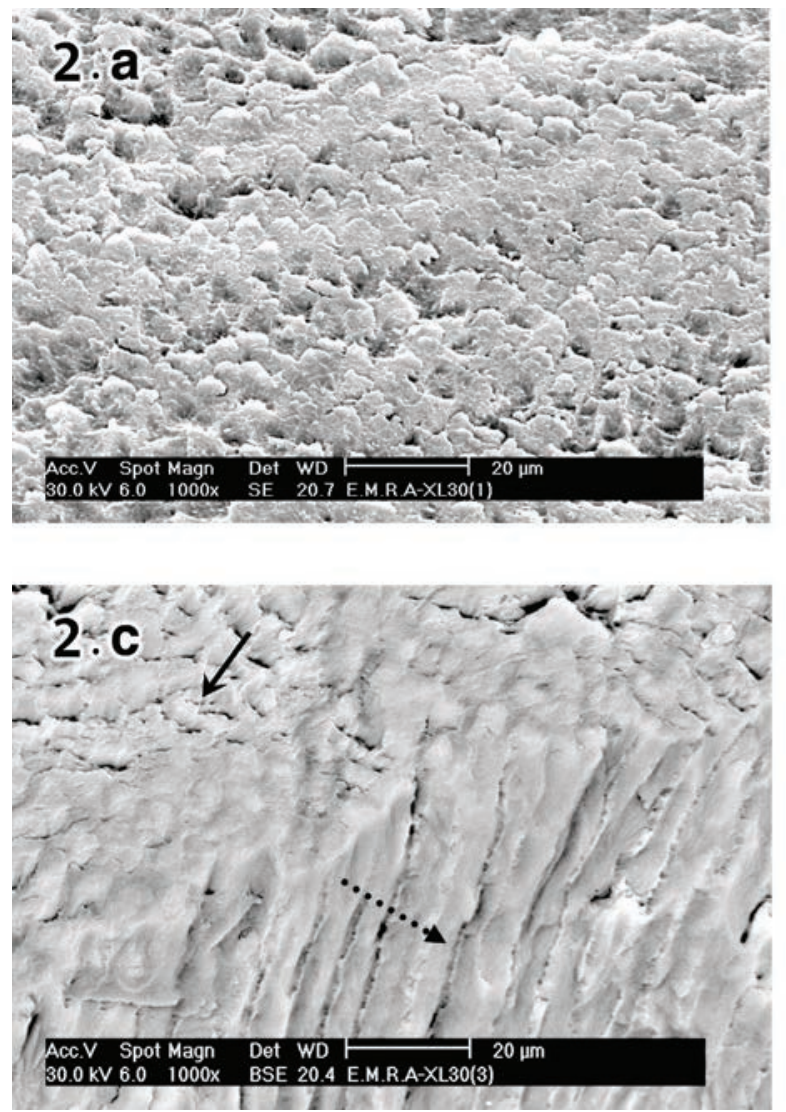

dent. Cracks may be attributed to the high vacuum employed for SEM examination. With EDTA pretreatment, topography (Figure 4e) had an evident non-homogeneous Type II etch pattern. Certain areas were markedly etched while others were very mildly involved with merely delineation of the prismatic morphology. The interface (Figure 4f) showed resin infiltration in the form of a very thin hybrid-like layer with very shallow sparse tag-like structures. A thick, uniform, and continuous adhesive layer was seen.

SEM photomicrographs of the surface topography and resin/enamel interface of the mild
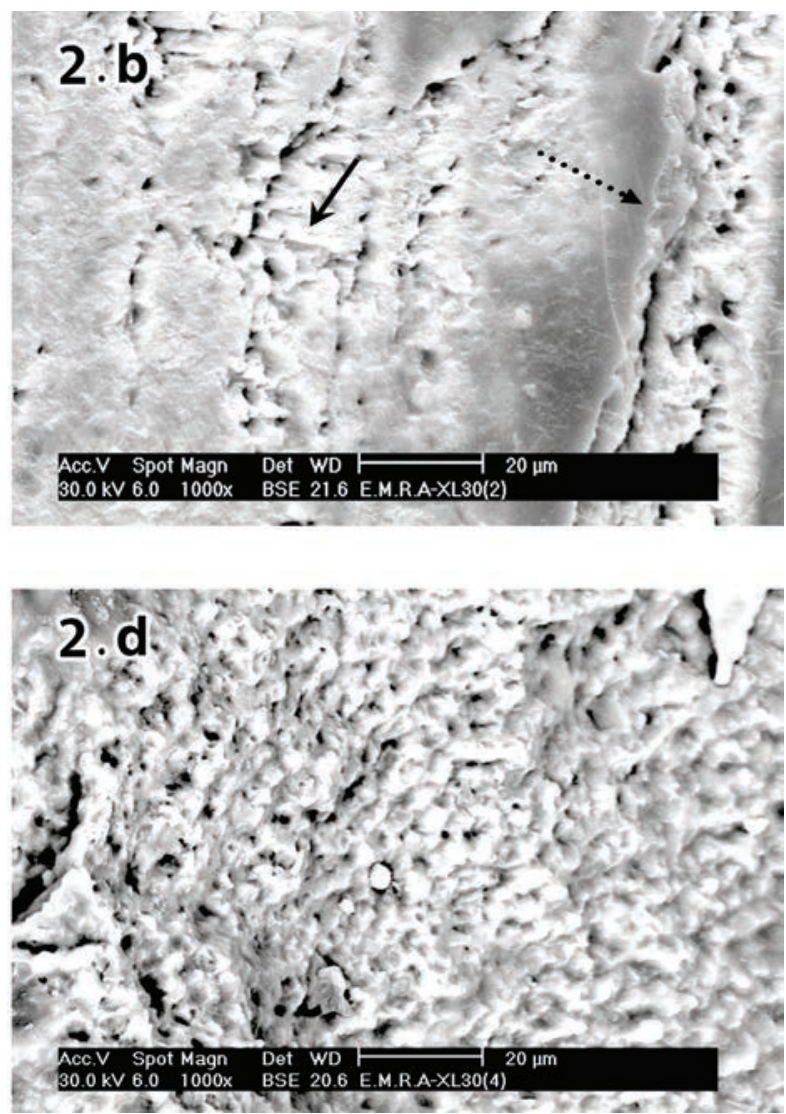

Figure 2. SEM photomicrographs of modes of failure: $2 a$, Type 1 failure (adhesive failure); $2 b$, Type 2 failure (partial adhesive failure between the bonding resin and enamel [solid arrow] and partial cohesive failure in bonding resin [dotted arrow]; 2c, Type 3 failure (partial adhesive failure between the bonding resin and the enamel [solid arrow] and partial cohesive failure in the enamel [dotted arrow]); and $2 \mathrm{~d}$, Type 5 failure (100\% cohesive failure in the enamel).

Table 3. Means and standard deviation (SD) values of shear bond strength values (MPa) for the different surface pretreatment agents with each adhesive system.

\begin{tabular}{|c|c|c|c|c|c|c|}
\hline \multirow{2}{*}{ Adhesive system } & \multicolumn{6}{|c|}{ Surface pretreatment } \\
\hline & \multicolumn{2}{|c|}{ No pretreatment } & \multicolumn{2}{|c|}{ Phosphoric acid } & \multicolumn{2}{|c|}{ EDTA } \\
\hline $\begin{array}{l}\text { Strong self-etching adhesive system } \\
\text { (Adper Prompt L-Pop) }\end{array}$ & $7.20^{c}$ & 1.90 & $7.40^{c}$ & 4.50 & $6.00^{d}$ & 2.30 \\
\hline $\begin{array}{l}\text { Mild self-etching adhesive system } \\
\text { (Frog) }\end{array}$ & $4.70^{\mathrm{e}}$ & 1.20 & $8.80^{\mathrm{b}}$ & 3.30 & $4.10^{\mathrm{e}}$ & 1.50 \\
\hline
\end{tabular}

Means with the same letters are not significantly different at $P \leq .05$. 
self-etching adhesive system are shown in Figure 5. With no surface pretreatment, the topography (Figure 5a) had a very mild irregular etch pattern not related to prism morphology (Type IV etch pattern) in the form of shallow craters with areas remaining unetched. The interface (Figure 5b) had resin infiltration in the form of a lamina-like, thin, and hybrid-like layer with no resin tag formation. A thin continuous adhesive layer was evident. With PA pretreatment, (Figure 5c) a homogeneous and regular Type II etch pattern with deep interprismatic dissolution was seen. The enamel appeared scaly with regularly-shaped repetitive motifs. The interface (Figure $5 d$ ) revealed resin infiltration in the form of a very thin hybrid-like layer. Numerous deeply penetrating tag-like structures were clear- ly seen. A thick, uniform, and continuous adhesive layer was also evident. With EDTA pretreatment, topography (Figure 5e) revealed preferential dissolution of interprismatic enamel (Type II) with areas remaining unetched. The interface (Figure $5 f$ ) showed a close resemblance to that of no surface pretreatment (Figure 5b).

\section{DISCUSSION}

This study evaluated the effect of surface pretreatments (PA or EDTA) on the bond strength of three self-etching adhesive systems to ground enamel surfaces. The self-etching adhesive systems were selected based on their $\mathrm{pH}$ values; one was chosen to represent each $\mathrm{pH}$ category. All of the selected adhesives had the same solvent
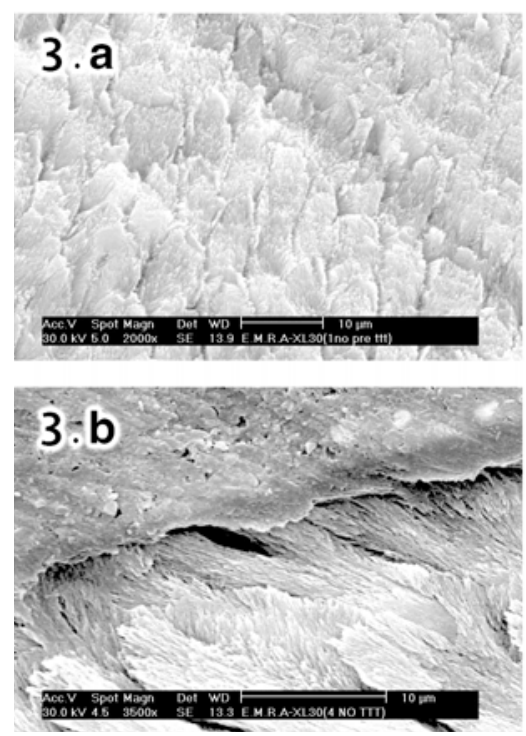
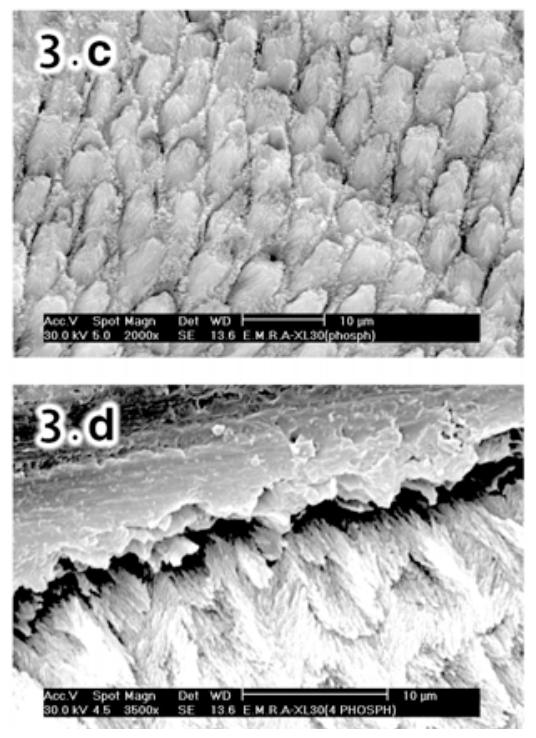
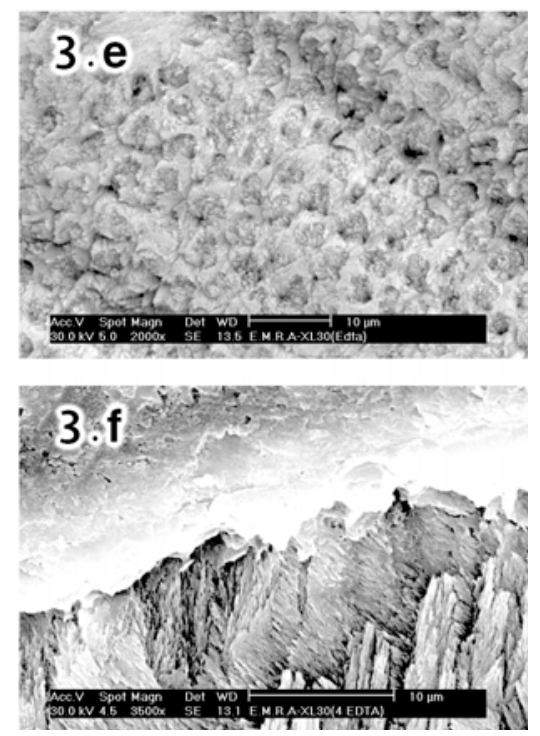

Figure 3. SEM of ground enamel surface topography and the resin/enamel interface with Adper Prompt L-pop adhesive: 3a and 3b, no pretreatment; 3c and 3d, pretreatment with phosphoric acid; and $3 e$ and $3 f$, pretreatment with EDTA.
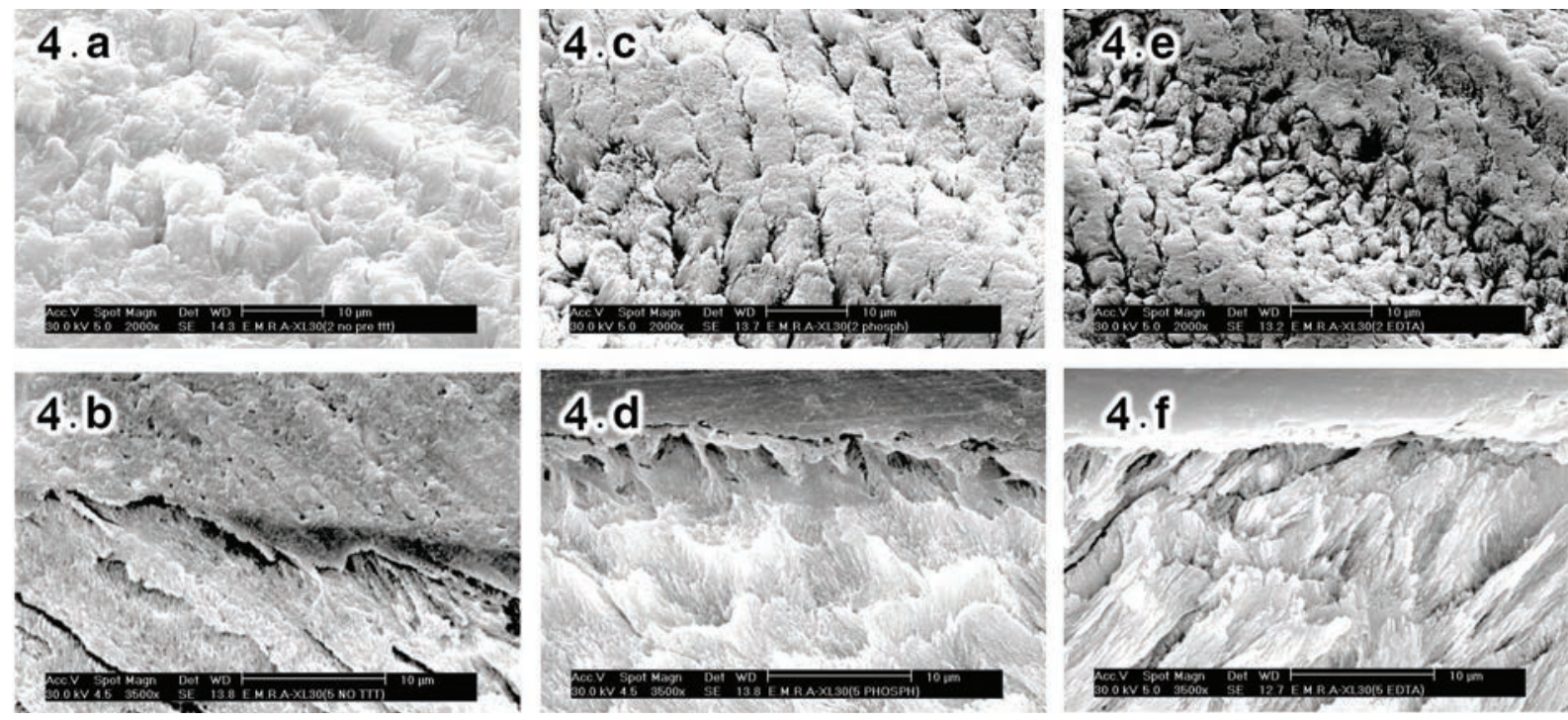

Figure 4. SEM of ground enamel surface topography and the resin/enamel interface with AdheSE adhesive: $4 \mathrm{a}$ and $4 \mathrm{~b}$, no pretreatment; $4 \mathrm{c}$ and $4 \mathrm{~d}$, pretreatment with phosphoric acid; $4 \mathrm{e}$ and 4f, pretreatment with EDTA. 
(water-based) and contained 2-hydroxyethylmethacrylate. Adhesives were also devoid of functional monomers that are claimed to chemically interact with tooth substrates.

Ground human enamel was utilized in this study. The buccal surface was ground parallel to the tooth long axis to flatten the enamel surface for shear testing and to standardize the orientation of enamel prisms. ${ }^{9}$ This process removes the outer hypermineralized and acid-resistant enamel and it is also consistent with clinical practice when the outer $0.5 \mathrm{~mm}$ of labial enamel is removed during bevelling or for veneering. ${ }^{17}$

Results of the present study revealed that PA pretreatment of the enamel surface led to a significant increase in bond strength values with the mild self-etching adhesive only, while EDTA pretreatment did not enhance the bond strength values of any of the tested self-etching adhesive systems. Thus, the first null hypothesis was partially accepted.

Both the strong and intermediary strong selfetching adhesive systems revealed definite etching patterns as depicted in Figures 3a and 4a. Pretreating enamel surfaces with PA led to further deepening of the same etching pattern created by both adhesive systems (Figures $3 c$ and $4 c$ ). This deepening was consistent with the increase in length of the tag-like structures at the interface (Figures 3d and 4d). However, this deepening did not significantly improve the bond strength. This observation is in agreement with that reported in Shinchi et $a l,{ }^{18}$ who showed that both the depth of etching and the length of the resin tags contribute little to bond strength in PA-etched enamel. In addition, Brackett et al ${ }^{19}$ found that the depth of etching and the subsequent depth of resin permeation induced by self-etching adhesive systems do not correlate with the attained bond strength. This may be due to the fact that increasing the depth of the resin tag does not contribute substantially to the increase in cumulative surface area created by acid etching of cut enamel. ${ }^{20} \mathrm{~A}$ marked increase in surface area is achieved via the creation of regular microporosities among the apatite crystallites; resins can infiltrate these microporosities and result in the formation of an enamel-resin composite consisting of inter- and intra-crystallite resin encapsulation as well as resin infiltration into the interprismatic boundaries. ${ }^{21}$ Moreover, it was recently reported that resin-to-enamel bonding with self-etching systems is based on a similar mechanism of inter- and intra-crystallite hybridization of the enamel surface rather than resin tag formation. ${ }^{22}$

This is in partial agreement with Perdigao et $\mathrm{al}^{2}{ }^{23}$ who found that PA pretreatment did not enhance the sealing ability of the strong self-etching adhesive system, APLP, in non-thermocycled specimens. However, this result is in disagreement with Lührs et $a{ }^{5}{ }^{5}$ who reported a significant increase in enamel shear bond strength of the strong single-step system Xeno III and the intermediary strong two- and one-step systems SE and Futurabond NR after additional PA etching. In addition, Erhardt et $\mathrm{al}^{13}$ reported significant
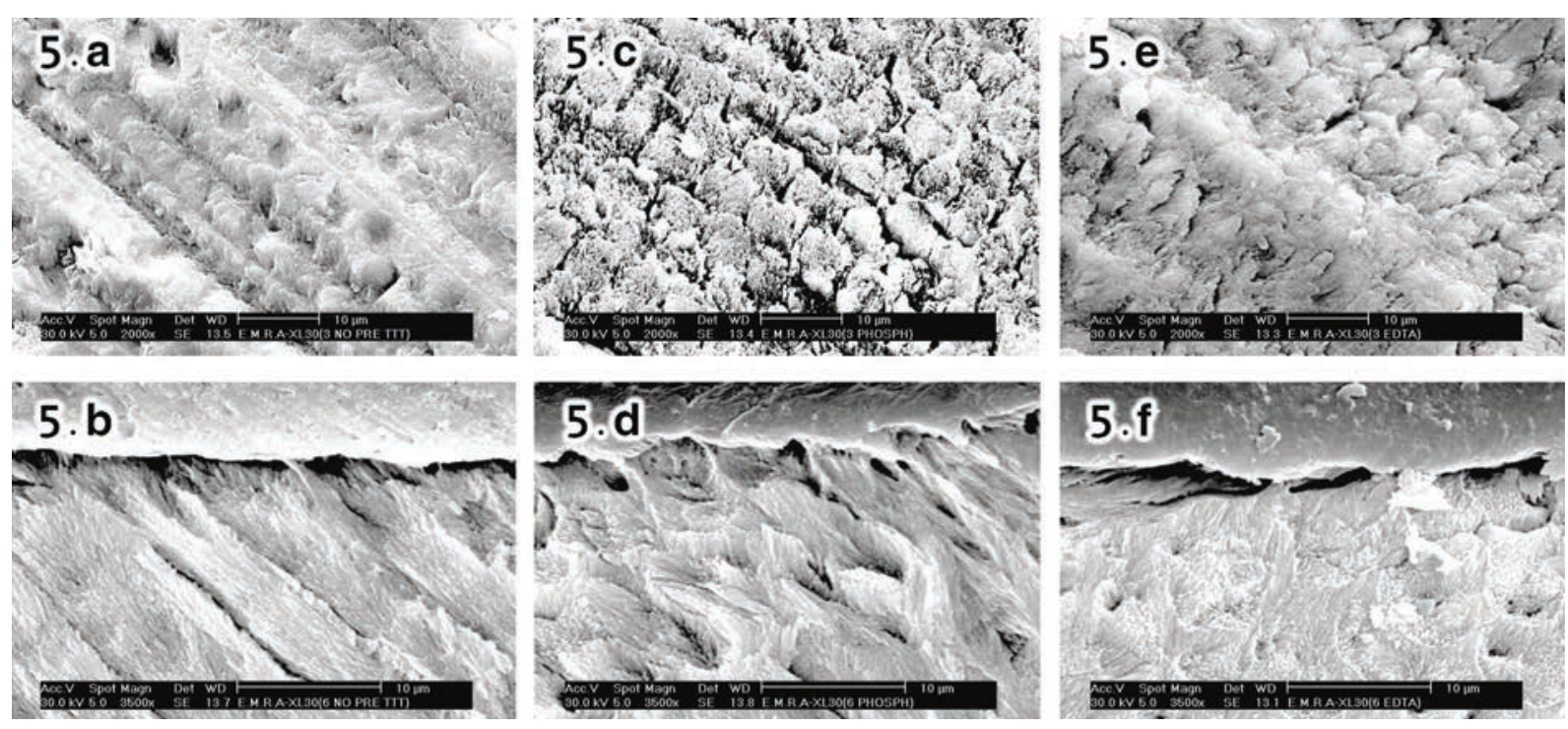

Figure 5. SEM of ground enamel surface topography and the resin/enamel interface using Frog adhesive: $5 \mathrm{a}$ and $5 \mathrm{~b}$, no pretreatment; $5 \mathrm{c}$ and $5 \mathrm{~d}$, pretreatment with phosphoric acid; and $5 e$ and $5 f$, pretreatment with EDTA. 
increases in enamel shear bond strength of the single-step intermediary strong self-etching adhesive One Up Bond F after PA pretreatment. This supports the fact that the bonding performance of adhesives is still material-dependant.

On the other hand, PA pretreatment enhanced the bond strength of the mild self-etching adhesive system in the current study, which is in agreement with other studies. ${ }^{13,24-29}$ The data from these studies collectively suggest that the mild self-etching adhesive systems used were unable to provide an adequate level of demineralization to achieve optimum bonding to enamel. Pretreatment with PA created adequate microporosities, which enhanced resin permeation. In the topographical SEM photomicrographs (Figures $5 \mathrm{a}$ and $5 \mathrm{c}$ ), PA pretreatment converted the etching pattern of the mild self-etching adhesive from an indefinite form (Type IV) to the more definite retentive form (Type II). This observation was also contiguous with the appearance of resin tags at the resin/enamel interface of PA-treated enamel (Figures $5 b$ and $5 d$ ).

Meanwhile, Erhardt et $\mathrm{al}^{13}$ explained this by the fact that PA might remove the smear layer, lowering its buffering capacity and leaving the enamel surface more receptive to self-etching primer diffusion. This result is, however, in contrast with Weerasinghe et al, ${ }^{17}$ who reported no statistically significant difference in enamel bond strength with PA pretreatment in conjunction with Clearfil SE Bond. However, Clearfil SE Bond contains the functional monomer 10-methacryloxydecyl dihydrogen phosphate (10-MDP), which is thought to chemically interact with tooth tissues.

The effect of EDTA pretreatment on enamel bond strength in conjunction with self-etching adhesive systems has not yet been addressed in the literature. However, studies that tested enamel etching with EDTA did not recommend its use because of the negligible non-uniform effect falling into the Type IV etching pattern category on ground enamel ${ }^{16}$ or the Type $V$ etching pattern category on unground enamel. ${ }^{15}$ These phenomena may be due to the neutral pH of EDTA (6.4-7.4). In addition, the concentration and application time might not have been sufficient to obtain a desirable effect on enamel. ${ }^{16}$ This result conforms to SEM findings of topography and interface (Figures 3e, $3 f, 4 e, 4 f, 5 e$, and 5f), as it was evident that EDTA pretreatment had a negligible and unpronounced effect when compared to the action of each of the three adhesive systems that were applied according to manufacturers' instructions (Figures 3a, 3b, $4 a, 4 b, 5 a$, and 5b) without further pretreatment, especially with the mild self-etching adhesive system (Figures $5 e$ and $5 f$ ).

When the three self-etch adhesives were applied according to manufacturer instructions, the intermediary strong system (SE) showed the best performance followed by the strong self-etching adhesive system (APLP). Meanwhile, the mild adhesive system (FG) performed the worst. Thus, the second null hypothesis was rejected.

This result is in agreement with De Munck et $\mathrm{al}^{3}{ }^{3}$ who showed that the strong self-etching APLP adhesive system scored the lowest in microtensile bond strength of all of the experimental and control adhesives including the intermediary strong systems SE and Optibond Solo Plus SE. The authors speculated that etching aggressiveness does not entirely correlate with bonding effectiveness as the individual features of the adhesive resin itself plays a role. Variation in adhesive viscosity, surface tension, chemical interaction of acidic monomers with enamel, water concentration, and cohesive strength of the adhesive are all examples of such features. ${ }^{30}$

Although water is a major component of all self-etching adhesives that allows the ionization of the acidic monomers to perform a demineralizing reaction, strong self-etching adhesives have high solvent contents to promote the complete ionization of the acidic monomer. ${ }^{31}$ The high water content in APLP $(80 \%)$ could be difficult to remove by air blowing. ${ }^{30,32}$ This in turn could decrease the polymerization efficacy and degree of conversion, thus altering the mechanical properties of the adhesive..$^{33}$ In addition, excess water may also dilute the primer and reduce its effectiveness. ${ }^{34}$ It has also been speculated that the high acidity of unpolymerized monomers remaining at the oxygen inhibited layer after light curing may attack the polymerization initiation system of the resin composite, resulting in lower bond strength. ${ }^{32}$

APLP and FG contain PA ester as the acidic polymerizable monomer unlike SE, which contains phosphonic acid acrylates. The latter is reported to have improved hydrolytic stability and reactivity in free radical polymerization. Moreover, SE also contains the hydrolytically stable cross-linking monomer bis-acrylamide. ${ }^{4,10}$ 
The strong system APLP is a single-step system (all-in-one) while the intermediary strong system SE is a two-step system. Van Landuyt et al ${ }^{24}$ reported that the amounts of ingredients applied on the tooth surface differ considerably between one- and two-step adhesives. Two-step adhesives consist of pure priming solution containing only functional etching monomers dissolved in organic solvent and water, and a solvent-free bonding containing hydrophobic cross-linking monomers that allow for a thicker and more hydrolytically stable adhesive layer. This layer can probably act as a shock absorber between tooth tissues and composites. On the other hand, one-step adhesives are complex mixtures of both hydrophobic and hydrophilic ingredients. ${ }^{?}$

On the other hand, this result is in contrast with findings of Goracci et al, ${ }^{10}$ Atash and Van den Abbeele, ${ }^{32}$ and Perdigão et al. ${ }^{35}$ The first two studies reported no significant difference in bond strength between APLP compared to SE. Meanwhile, Perdigão et al ${ }^{35}$ reported higher enamel bond strength with APLP than SE. This contradiction may be attributed to differences in testing methodologies and the substrate examined.

In the current study, the mild self-etching adhesive system (FG) showed the lowest bond strength compared to the strong and intermediary strong adhesive systems. This could be partially attributed to the relatively higher numbers of retentive etching patterns created by the strong and intermediary strong adhesive systems (Figures 3a and 4 a) compared to the indefinite non-retentive pattern created by the mild self-etching adhesive system (Figure 5a). The $\mathrm{pH}$ of the mild self-etching adhesives might be optimal for dentin but may not be sufficiently aggressive for enamel. ${ }^{19}$

\section{CONCLUSIONS}

- The intermediary strong, self-etching adhesive system (AdheSE) might have higher potential for bonding to enamel than the strong and mild, self-etching adhesive systems (Adper Prompt LPop and FG).

- Phosphoric acid pre-treatment could be beneficial for bonding to enamel using mild self-etching adhesive systems.

- EDTA pre-treatment is not a viable alternative for enamel bonding to self-etching adhesive systems.
- The uniformity rather than the depth of the etching pattern affected the bonding of self-etching adhesives to enamel.

\section{ACKNOWLEDGEMENTS}

This study was based on a thesis by lhab $M$. Ibrahim submitted to Cairo University, in partial fulfillment of the requirements of the Master Degree of Science.

\section{REFERENCES}

1. De Munck J, Van Landuyt K, Peumans M, Poitevin A, Lambrechts $\mathrm{P}$, Braem M, Van Meerbeek B. A critical review of the durability of adhesion to tooth tissue: methods and results. J Dent Res 2005;84:118-132.

2. Van Meerbeek B, De Munck J, Yoshida Y, Inoue S, Vargas $M$, Vijay $P$, Van Landuyt $K$, Lambrechts $P$, Vanherle G. Buonocore memorial lecture. Adhesion to enamel and dentin: current status and future challenges. Oper Dent 2003;28:215-235.

3. De Munck J, Vargas M, Iracki J, Van Landuyt K, Poitevin A, Lambrechts P, Van Meerbeek B. One-day bonding effectiveness of new self-etch adhesives to bur-cut enamel and dentin. Oper Dent 2005;30:39-49.

4. Moszner N, Salz U, Zimmermann J. Chemical aspects of self-etching enamel-dentin adhesives: a systematic review. Dent Mater 2005;21:895-910.

5. Lührs A-K, Guhr S, Schilke R, Borchers L, Geurtsen W, Günay $H$. Shear bond strength of self-etch adhesives to enamel with additional phosphoric acid etching. Oper Dent 2008;33:155-162.

6. Ibarra G, Vargas MA, Armstrong SR, Cobbb DS. Microtensile bond strength of self-etching adhesives to ground and unground enamel. J Adhes Dent 2002;4:115-124.

7. Wang H, Shimada Y, Tagami J. Shear bond stability of current adhesive systems to enamel. Oper Dent 2004;29:168175.

8. Kiremitçi A, Yalçin F, Gökalp S. Bonding to enamel and dentin using self-etching adhesive systems. Quintessence Int 2004;35:367-370.

9. De Munck J, Van Meerbeek B, Satoshi I, Vargas M, Yoshida Y, Armstrong S, Lambrechts P, Vanherle G. Microtensile bond strengths of one- and two-step self-etch adhesives to bur-cut enamel and dentin. Am J Dent 2003;16:414-420.

10. Goracci C, Sadek FT, Monticelli F, Cardoso PE, Ferrari M. Microtensile bond strength of self-etching adhesives to enamel and dentin. J Adhes Dent 2004;6:313-318.

11. Perdigão J, Gomes G, Duarte S Jr, Lopes MM. Enamel bond strengths of pairs of adhesives from the same manufacturer. Oper Dent 2005;30:492-499. 
12. Erickson RL, De Gee AJ, Feilzer AJ. Fatigue testing of enamel bonds with self-etch and total-etch adhesive systems. Dent Mater 2006;22:981-987.

13. Erhardt MC, Cavalcante LM, Pimenta LA. Influence of phosphoric acid pretreatment on self-etching bond strengths. $J$ Esthet Restor Dent 2004;16:33-41.

14. Ernst CP. Positioning self-etching adhesives: versus or in addition to phosphoric acid etching? J Esthet Restor Dent 2004; 16:57-69.

15. Cehreli ZC, Altay N. Effects of a nonrinse conditioner and $17 \%$ ethylenediaminetetraacetic acid on the etch pattern of intact human permanent enamel. Angle Orthod 2000;70:2227.

16. Bogra P, Kaswan S. Etching with EDTA--an in vitro study. $J$ Indian Soc Pedo Prev Dent 2003;21:79-83.

17. Weerasinghe DS, Nikaido T, Wettasinghe KA, Abayakoon JB, Tagami J. Micro-shear bond strength and morphological analysis of a self-etching primer adhesive system to fluorosed enamel. J Dent 2005;33:419-426.

18. Shinchi MJ, Soma K, Nakabayashi N. The effect of phosphoric acid concentration on resin tag length and bond strength of a photo-cured resin to acid-etched enamel. Dent Mater 2000;16:324-329.

19. Brackett WW, Tay FR, Looney SW, Ito S, Haisch LD, Pashley $\mathrm{DH}$. Microtensile dentin and enamel bond strengths of recent self-etching resins. Oper Dent 2008;33:89-95.

20. Nygaard VK, Simmelink JW. Ultrastructural study of the resin infiltration zone in acid-treated human enamel. Arch Oral Biol 1978;23:1151-1156.

21. Gwinnett AJ, Matsui A. A study of enamel adhesives. The physical relationship between enamel and adhesive. Arch Oral Biol 1967;12:1615-1620.

22. Hannig M, Bock H, Bott B, Hoth-Hannig W. Inter-crystallite nanoretention of self-etching adhesives at enamel imaged by transmission electron microscopy. Eur J Oral Sci 2002;110:464-470.

23. Perdigão J, Monteiro P, Gomes G. In vitro enamel sealing of self-etch adhesives. Quintessence Int 2009;40:225-233.

24. Van Landuyt KL, Peumans M, De Munck J, Lambrechts $P$, Van Meerbeek B. Extension of a one-step self-etch adhesive into a multi-step adhesive. Dent Mater 2006;22:533544.

25. Glasspoole EA, Erickson RL, Davidson CL. Effect of enamel pretreatments on bond strength of compomer. Dent Mater 2001;17:402-408.

26. Torii Y, Itou K, Nishitani Y, Ishikawa K, Suzuki K. Effect of phosphoric acid etching prior to self-etching primer application on adhesion of resin composite to enamel and dentin. Am J Dent 2002;15:305-308.
27. Miguez PA, Castro PS, Nunes MF, Walter R, Pereira PN. Effect of acid-etching on the enamel bond of two self- etching systems. J Adhes Dent 2003;5:107-112.

28. Van Landuyt KL, Kanumilli P, De Munck J, Peumans M Lambrechts $P$, Van Meerbeek B. Bond strength of a mild self-etch adhesive with and without prior acid-etching. $J$ Dent 2006;34:77-85.

29. Erickson RL, Barkmeier WW, Kimmes NS. Bond strength of self-etch adhesives to pre-etched enamel. Dent Mater 2009;25:1187-1194.

30. Loguercio AD, Moura SK, Pellizzaro A, Dal-Bianco K, Patzlaff RT, Grande RH, Reis A. Durability of enamel bonding using two-step self-etch systems on ground and unground enamel. Oper Dent 2008;33:79-88.

31. Kenshima S, Reis A, Uceda-Gomez N, Tancredo Lde L, Filho LE, Nogueira FN, Loguercio AD. Effect of smear layer thickness and $\mathrm{pH}$ of self-etching adhesive systems on the bond strength and gap formation to dentin. $J$ Adhes Dent 2005;7:117-126.

32. Atash R, Van den Abbeele A. Bond strengths of eight contemporary adhesives to enamel and to dentine: an in vitro study on bovine primary teeth. Int $J$ Paediatr Dent 2005; 15:264-273.

33. Sadr A, Shimada Y, Tagami J. Effects of solvent drying time on micro-shear bond strength and mechanical properties of two self-etching adhesive systems. Dent Mater 2007;23:1114-1119.

34. Kaaden C, Powers JM, Friedl KH, Schmalz G. Bond strength of self-etching adhesives to dental hard tissues. Clin Oral Investig 2002;6:155-160.

35. Perdigão J, Gomes G, Lopes MM. Influence of conditioning time on enamel adhesion. Quintessence Int 2006;37:35-41. 